\title{
The influence of macronutrient intake on the well-being and cognitive performance of recreational mountain marathon competitors
}

\author{
E. A. Mahon, A. F. Hackett and I. G. Davies \\ Liverpool John Moores University, I.M. Marsh Campus, Aigburth, Liverpool L176BD, UK
}

While the majority of sports nutrition research assesses the effects of nutrition on physical performance, there have been fewer studies focusing on cognitive performance and general well-being, the latter perhaps being as, if not more, important to the recreational athlete than overall performance. Recent years have shown an increasing trend in the number of hill-walking/mountain incidents and cognitive fatigue may be a causal factor of such incidents as it is key in areas of orientation, safety, decision-making and reactions to challenging situations $^{(1,2)}$.

Twenty-three participants (19 males, 4 females; ages: 18-72 years) entered in the Longmynd Hike [50 mile race; mean completion time: 16.0 (SD: 3.2) h] completed a weighed food inventory of all items consumed during the event. Cognitive performance tests (e.g. reaction time tasks and Stroop tests) and subjective ratings of well-being using a visual-analogue scale were performed before and after the race. A post-race questionnaire provided information on incidents and symptoms experienced and participants provided a perceived rate of exertion score using the Borg 6-20 scale ${ }^{(3)}$. All data are expressed as means (SD), statistical significance $P<0.05$.

Macronutrient intakes are shown below. No significant differences in nutrient intakes were seen between age groups or males and females. Total protein $(\mathrm{g} / \mathrm{kg} / \mathrm{h})$ showed positive correlation with perceived rate of exertion $(P<0.01)$ and post-race scores of tiredness and mental fatigue $(P<0.05)$. No associations were found with intakes of fat, $\mathrm{CHO}$ or energy and well-being markers. Energy $(\mathrm{kJ} / \mathrm{kg} / \mathrm{h})$ and $\mathrm{CHO}(\mathrm{g} / \mathrm{kg} / \mathrm{h})$ were negatively associated with time taken to complete the post-race reaction time test indicating they may be beneficial in sustaining vigilance and perception during prolonged exercise. Such attributes appear to be important in mountain marathon events as significant differences were seen in post-race reaction time between those reporting losing their way [4180.5 (1025.2) ms] and those not [3386.2 (742.3) $\mathrm{ms} ; P<0.01]$.

\begin{tabular}{lccccccc}
\hline Energy $(\mathrm{kJ} / \mathrm{kg} / \mathrm{h})$ & & \multicolumn{2}{c}{ CHO $(\mathrm{g} / \mathrm{kg} / \mathrm{h})$} & \multicolumn{2}{c}{ Fat $(\mathrm{g} / \mathrm{kg} / \mathrm{h})$} & \multicolumn{2}{c}{ Protein $(\mathrm{g} / \mathrm{kg} / \mathrm{h})$} \\
\hline Mean & SD & Mean & SD & Mean & SD & Mean & SD \\
9 & 4.4 & 0.38 & 0.22 & 0.06 & 0.04 & 0.055 & 0.05 \\
\hline
\end{tabular}

Previous research regarding cognitive function and diet composition at rest has reported limited evidence regarding the effects of macronutrients ${ }^{(4)}$. However, the findings from this study suggest that perhaps in a fatigued, potentially energy-deficient state, the macronutrient composition of the diet may play a more significant role. It appears that increasing $\mathrm{CHO}$ and decreasing protein consumption during endurance events may help to improve cognitive performance and well-being, respectively.

1. Mountain Rescue (2007) Incident Report 2006. http://www.mountain.rescue.org.uk/publications/2006\%20Annual\%20Report.pdf (accessed April 2009).

2. Makinen TM, Palinkas LA, Reeves DL et al. (2006) Effect of repeated exposures to cold on cognitive performance in humans. Physiol Behav 87, 166176.

3. Borg G (1970) Perceived Exertion as an indicator of somatic stress. Scand J Rehabil Med 2, 92-98.

4. Lieberman HR (2007) Cognitive methods for assessing mental energy. Nutr Neurosci 10, $229-242$. 